Supplemental information for

\title{
Relationships between Substrate, Surface Characteristics, and Vegetation in an Initial Ecosystem
}

by

\author{
P. Biber, S. Seifert, M. K. Zaplata, W. Schaaf, H. Pretzsch, and A. Fischer
}

This supplement gives an extensive graphical presentation of the data used in this study. While the Figures listed here are not necessary to understand the main article, they may be helpful for readers who would like to get a more detailed view. Each supplemental figure is referenced in the main text, corresponding variable definitions and summarizing tables can be taken there from Tables 1, 2, and 3. Unused grid points as shown in some figures were not measured due to intensive monitoring instrumentation in these places.

\section{Figure Captions}

Figure S1: Total degree of plant cover COVTOT [\%] (cf. Tables 1, 3) in spatio-temporal display.

Figure S2: Degree of cover by annual plants COVANN [\%] (cf. Table 3) in spatio-temporal display.

Figure S3: Degree of cover by herbaceaous plants COVHERB [\%] (cf. Table 3) in spatiotemporal display.

Figure S4: Degree of cover by Fabaceae COVFAB [\%] (cf. Table 3) in spatio-temporal display.

Figure S5: Degree of cover by perennial plants COVPER [\%] (cf. Table 3) in spatio-temporal display.

Figure S6: Degree of cover by grasslike plants COVGRASS [\%] (cf. Table 3) in spatiotemporal display.

Figure S7: Degree of cover by woody plants COVWOOD [\%] (cf. Table 3) in spatio-temporal display.

Figure S8: Proportion of annual plant cover related to total plant cover (PROPANN, cf.

Tables 1, 2) in spatio-temporal display.

Figure S9: Proportion of herbaceous plant cover related to total plant cover (PROPHERB, cf. Tables 1, 2) in spatio-temporal display. 
Figure S10: Proportion of grasslike plant cover related to total plant cover (PROPGRASS, cf. Tables 1, 2) in spatio-temporal display.

Figure S11: Proportion of cover of plants belonging to the Fabaceae family related to total plant cover (PROPFAB, cf. Tables 1, 2) in spatio-temporal display.

Figure S12: Proportion of cover of woody plants related to total plant cover (PROPWOOD, cf. Tables 1, 2) in spatio-temporal display.

Figure S13: Soil properties Percentage of organic carbon in the soil (CORGP), Percentage of gravel content in the soil (GRAVCONT), and Percentage of medium sand $(0.2-0.63 \mathrm{~mm})$ in the soil (MSAND) as measured in 2005 (cf. Tables 1, 2) in spatio-temporal display.

Figure S14: Mean annual ground water level below surface GAUGE [m] (cf. Tables 1, 2) in spatio-temporal display.

Figure S15: Laser-scanned mean vegetation height VEGHEIGHT [m] (cf. Tables 1, 2) in spatio-temporal display.

Figure S16: Laser-scanned mean vegetation density VEGDENS (cf. Tables 1, 2) in spatiotemporal display.

Figure S17: Product of the mean vegetation height und vegetation density VEGDH (cf. Tables $1,2)$ in spatio-temporal display.

Figure S18: Proportion of laser scan cells classified as belonging to a rill related to the total amount of laser scan cells per vegetation plot RILLR (cf. Tables 1, 2) in spatio-temporal display.

Figure S19: Mean value of local relief energy RELEN (cf. Tables 1, 2) in spatio-temporal display.

Figure S20: Mean ground surface elevation changes DHEIGHT [m] (cf. Tables 1, 2) between September 2008 - May 2009, May 2009 - April 2010, and April 2010 - February 2011 in spatio-temporal display. Positive values of DHEIGHT indicate an increase of the surface height indicating a net gain of substrate material in the vegetation square, while negative values indicate a net substrate material export (erosion) from the respective square.

Figure S21: Initial network of erosion channels in November 2005. The circles indicate the perpendicular erosion channels in the upper part and rectangles mark the parallel channels in the lower western part of the area corresponding to caterpillar tracks. Figure taken from Schaaf et al. (2012).

Figure S22: Boxplot of the rill cell frequency (RILLR) against the distance to the grid row A on the catchment (see Figure 1). Due to other confounding variables the minimum around DISTA values about $50-150 \mathrm{~m}$ is less visible than in the results of the statistical analysis (Figure 2).

Figure S23: Boxplot of local relief energy (RELEN) against the distance to the grid row A on the catchment (see Figure 1). Due to other confounding variables the minimum around 
DISTA values about $50-150 \mathrm{~m}$ is less visible than in the results of the statistical analysis (Figure 3). 


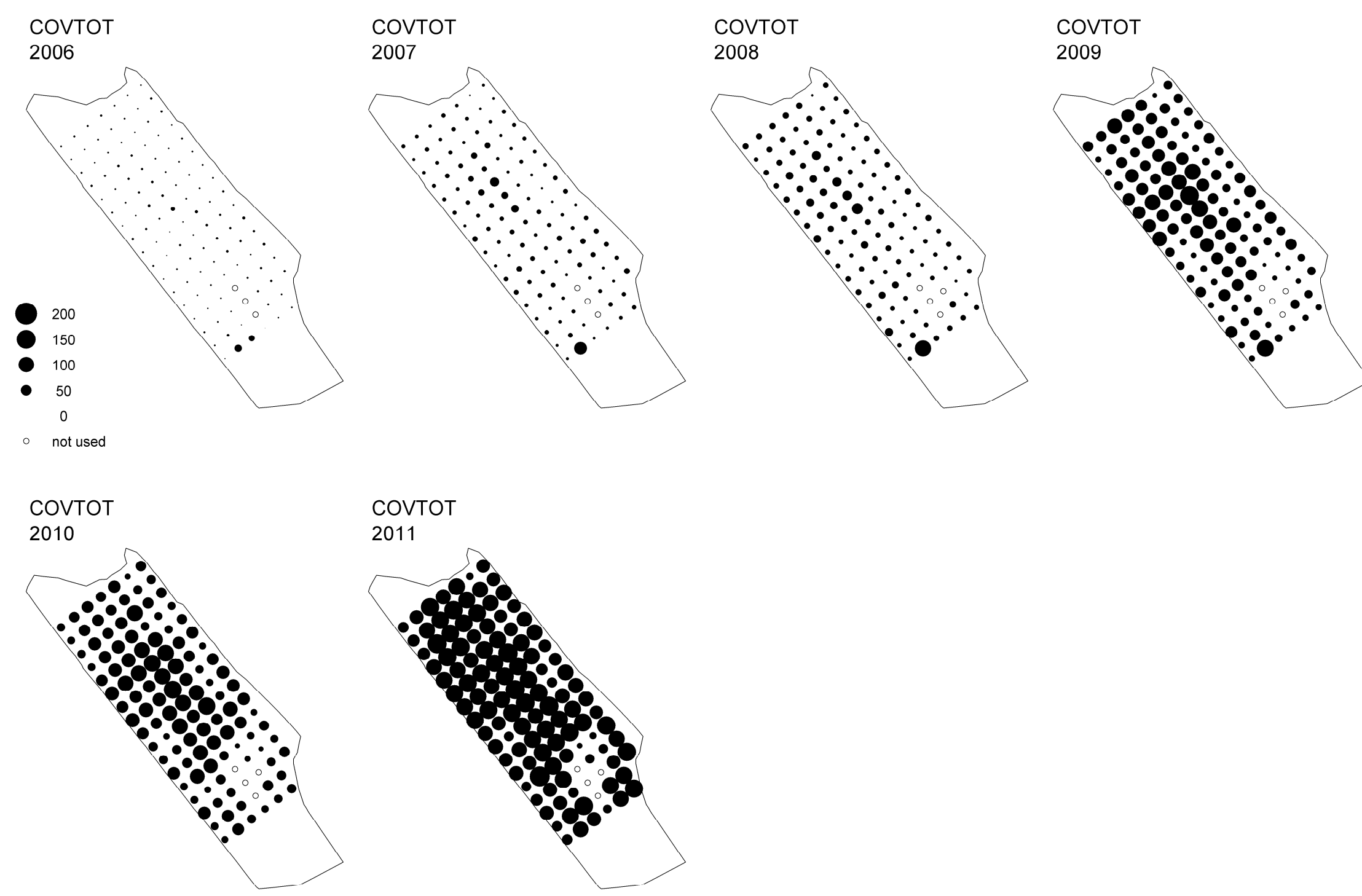

Figure S1 


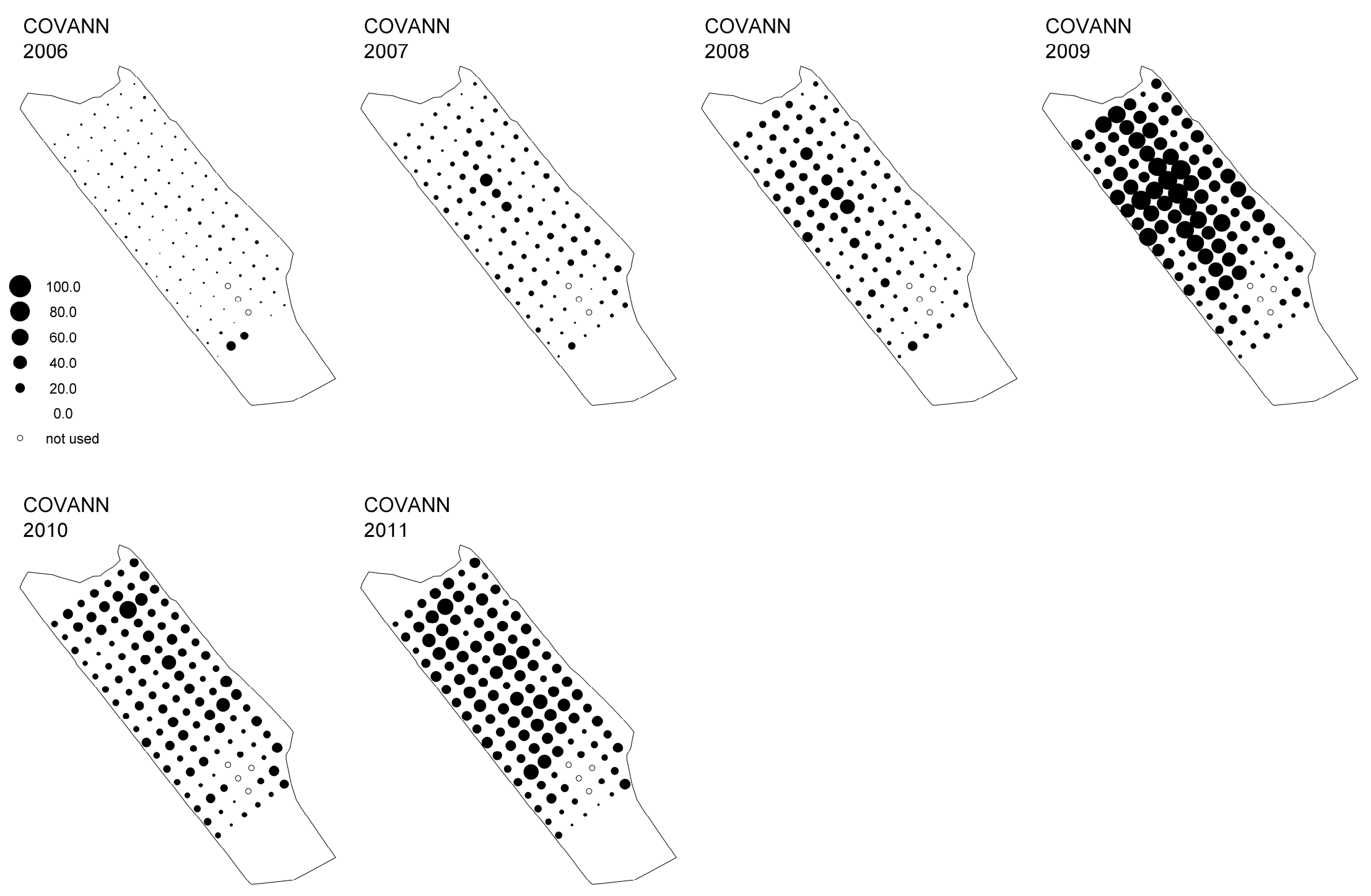

Figure S2

5 

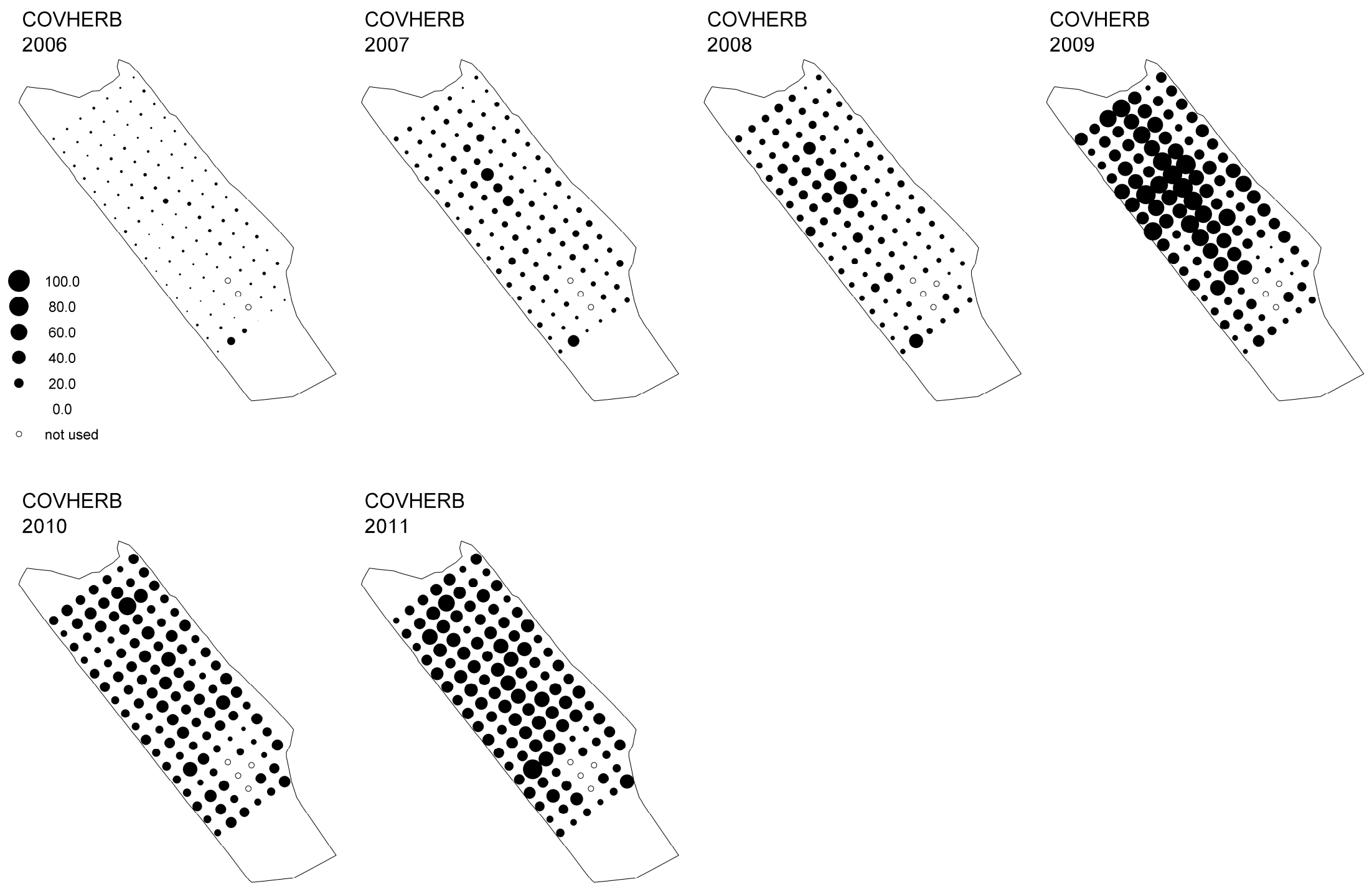

Figure S3

6 


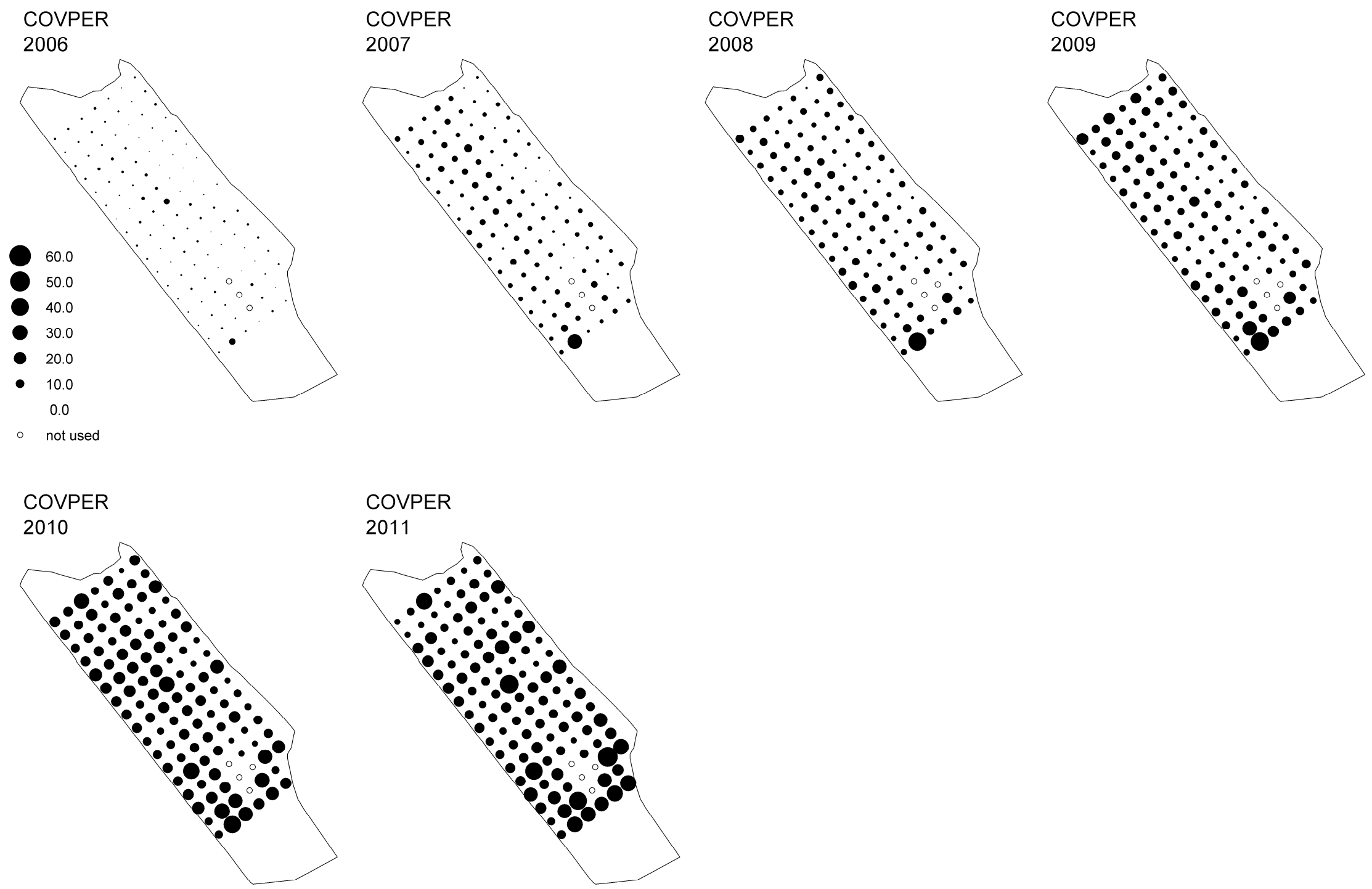

Figure S5

8 


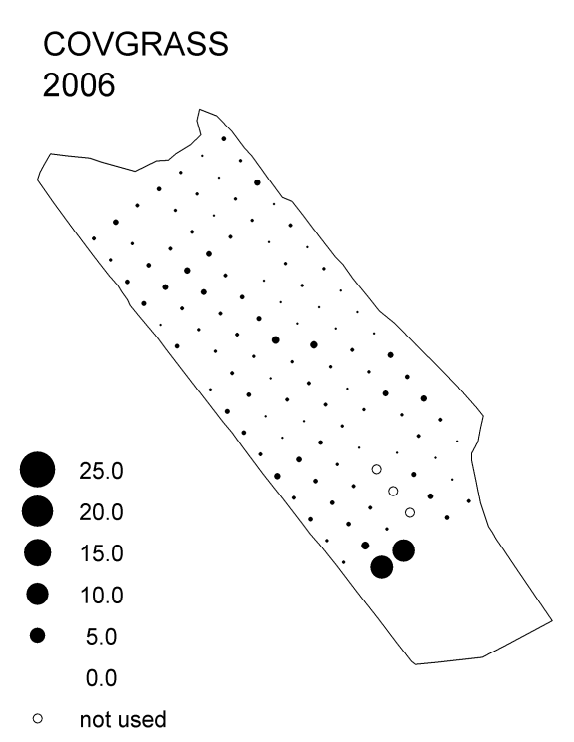

$$
\begin{aligned}
& \text { COVGRASS } \\
& 2007
\end{aligned}
$$

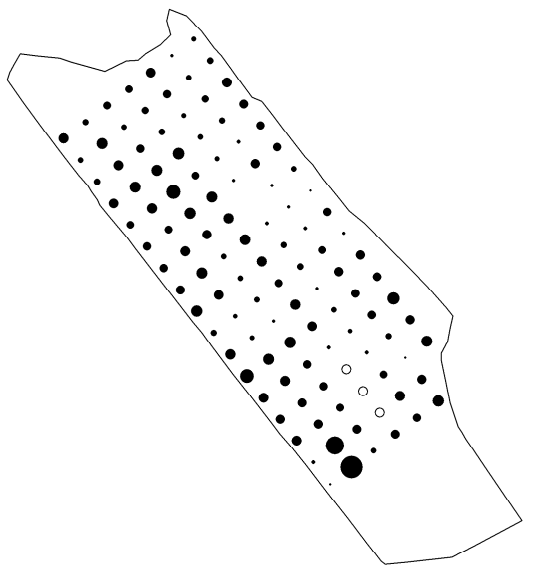

COVGRASS
2008

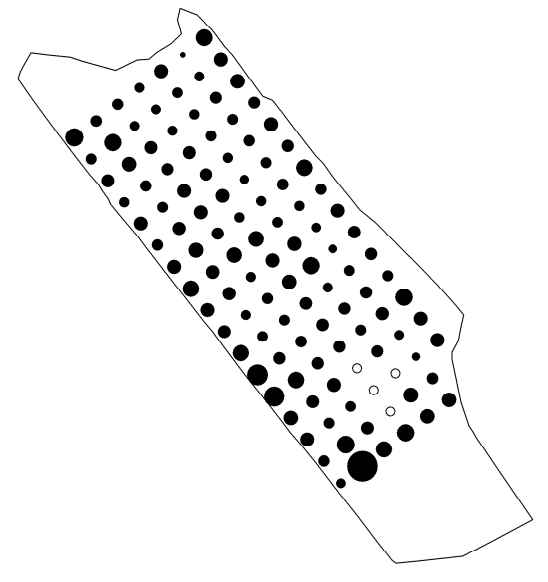

COVGRASS

2009

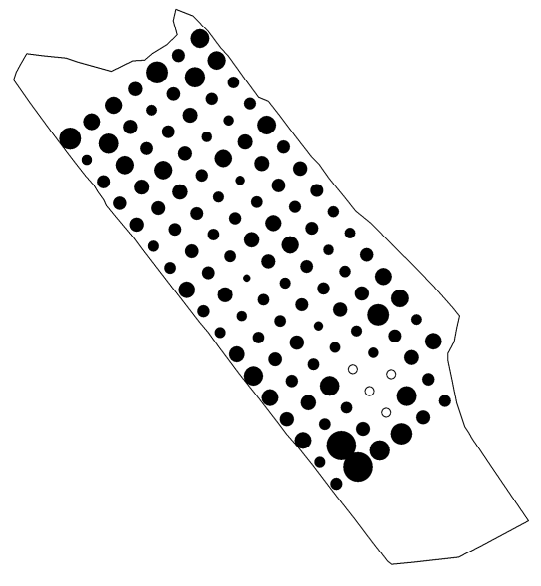

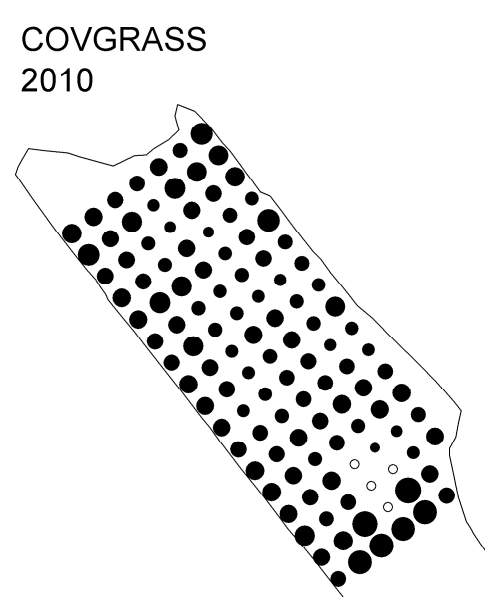

COVGRASS

2011

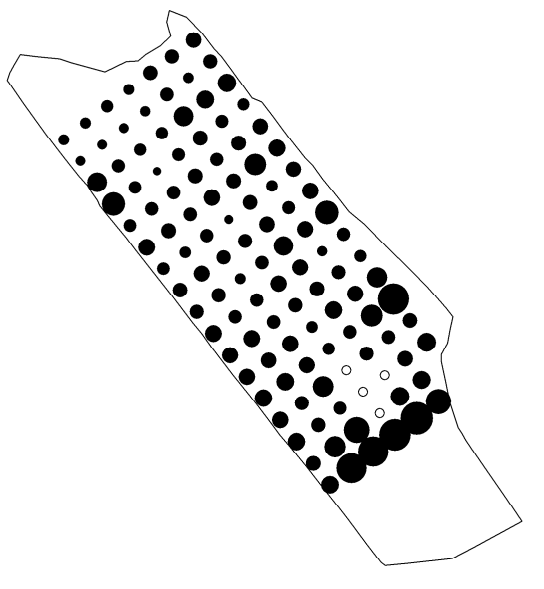

Figure S6 

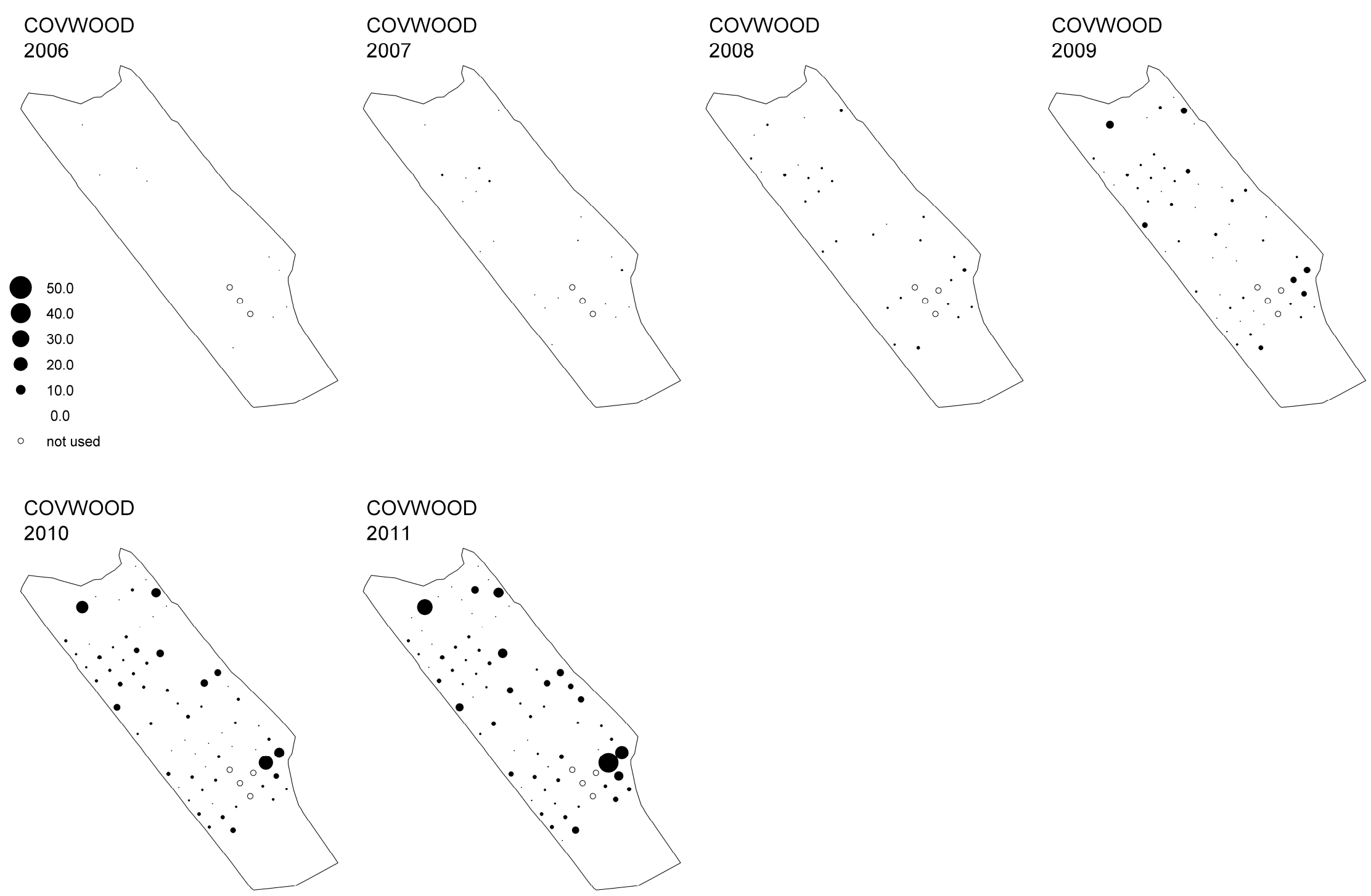

Figure S7

10 


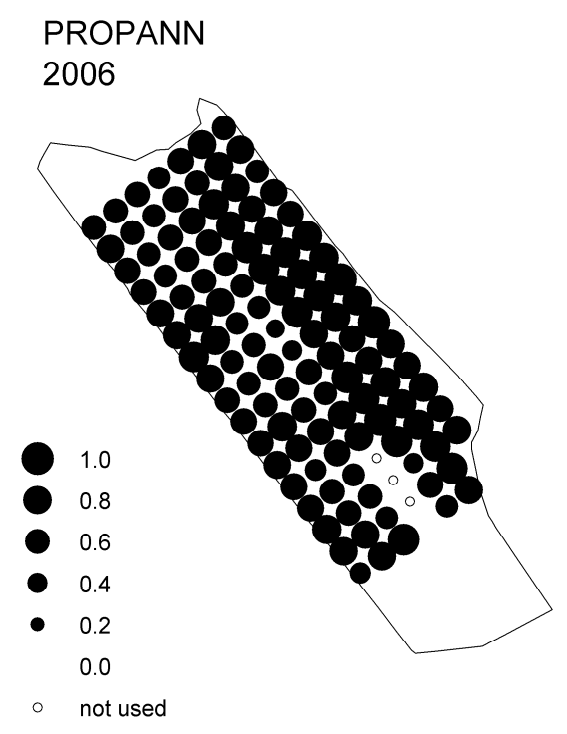

\section{PROPANN \\ 2007}

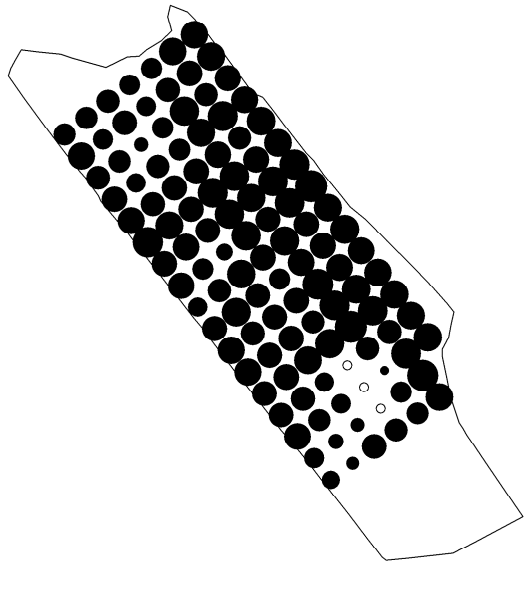

PROPANN

PROPANN

2010
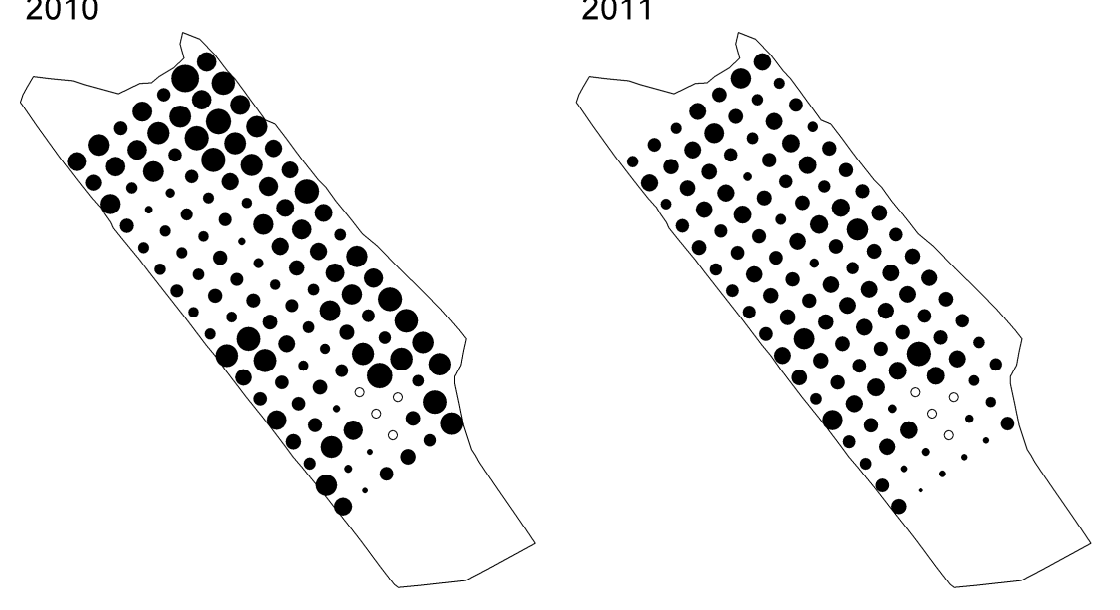

PROPANN

2008

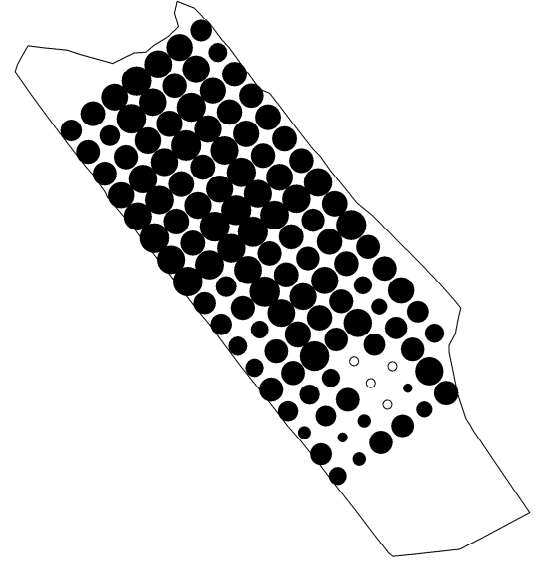

PROPANN

2009

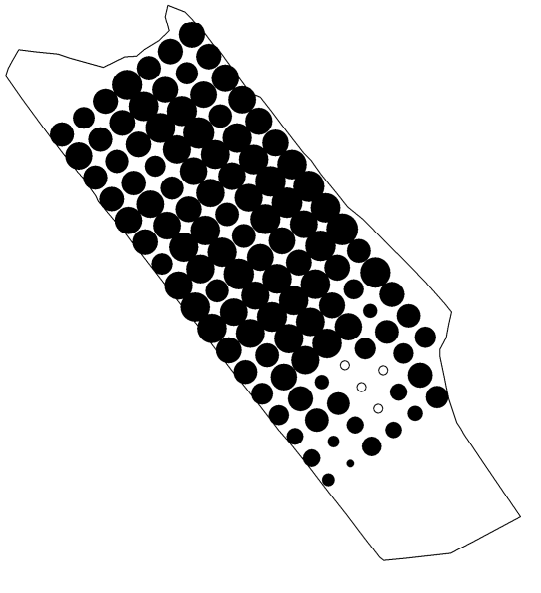

Figure S8 


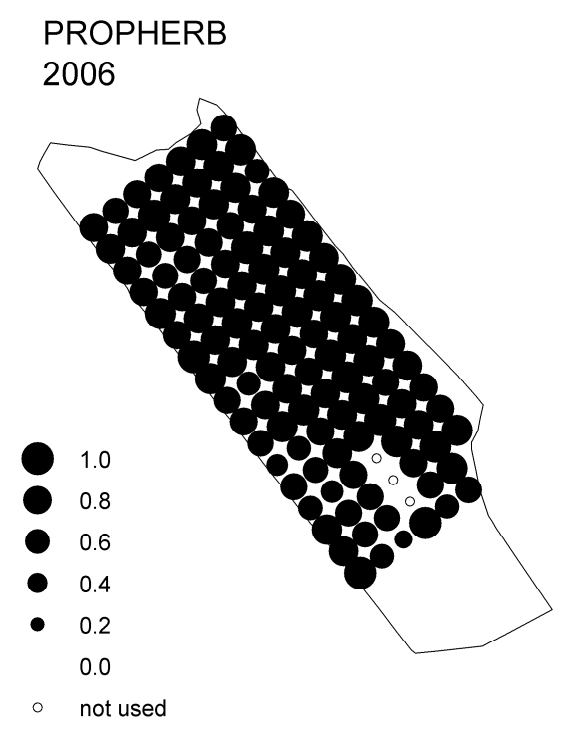

PROPHERB
2007

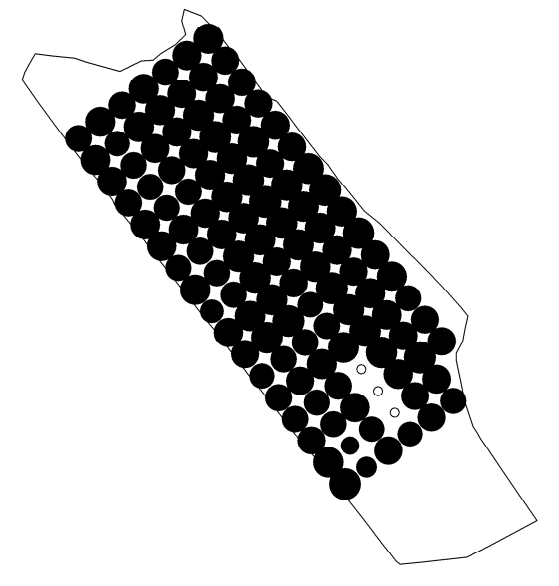

PROPHERB

2008

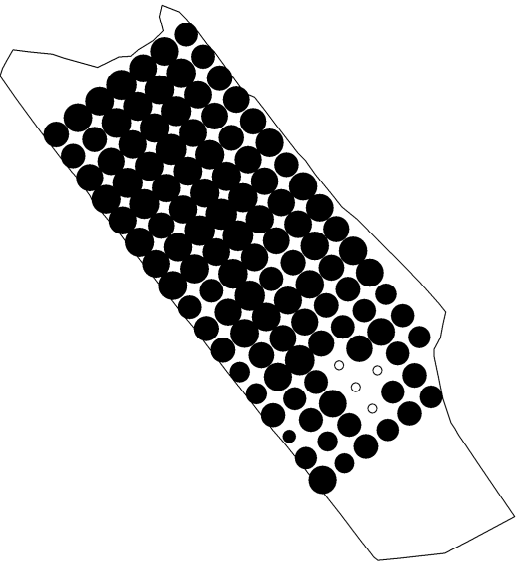

PROPHERB

2009

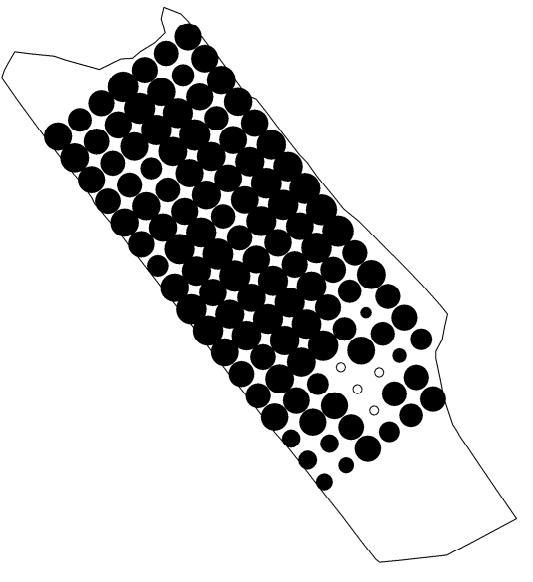

PROPHERB

2010

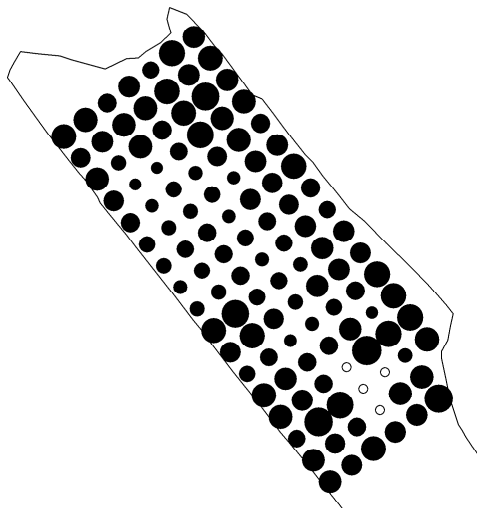

PROPHERB

2011

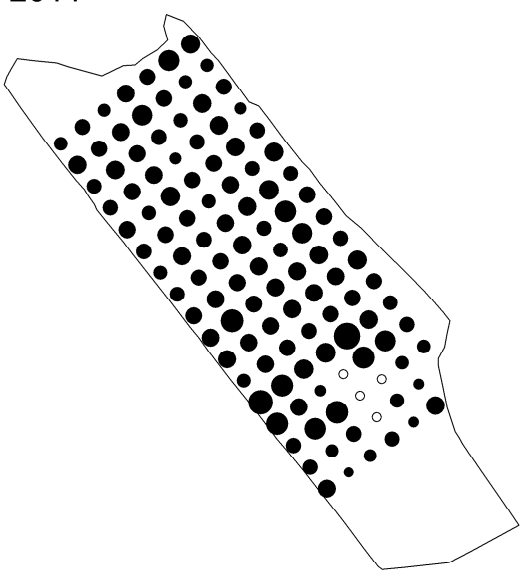

Figure S9 


\section{PROPGRASS \\ 2006}

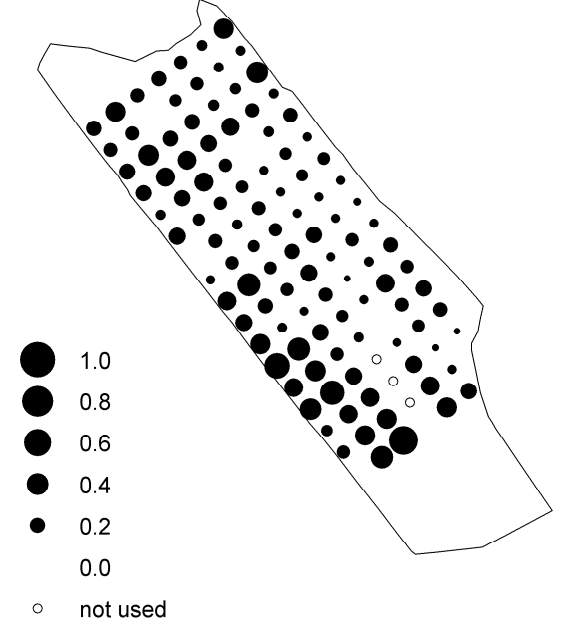

PROPGRASS

2010

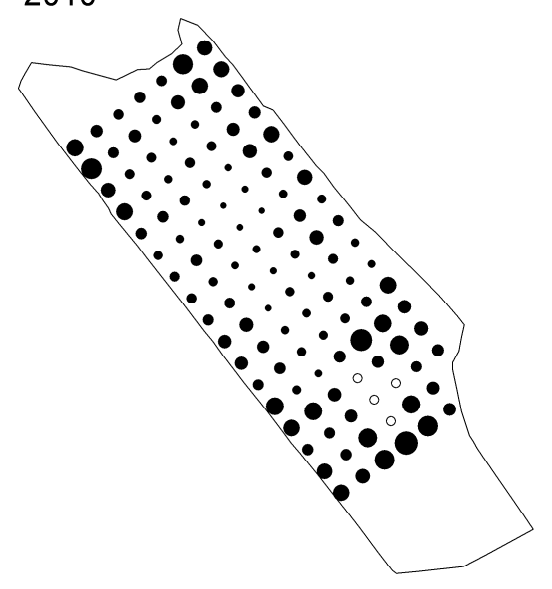

PROPGRASS

2007

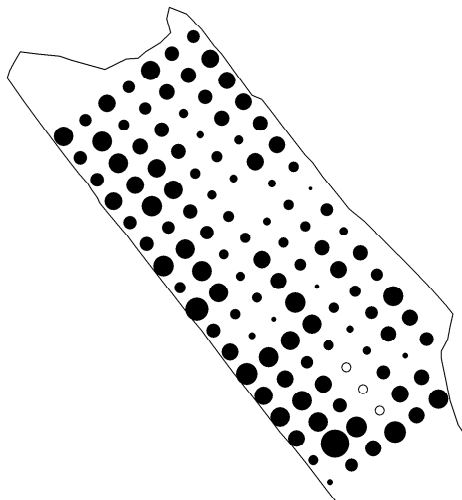

PROPGRASS

2008

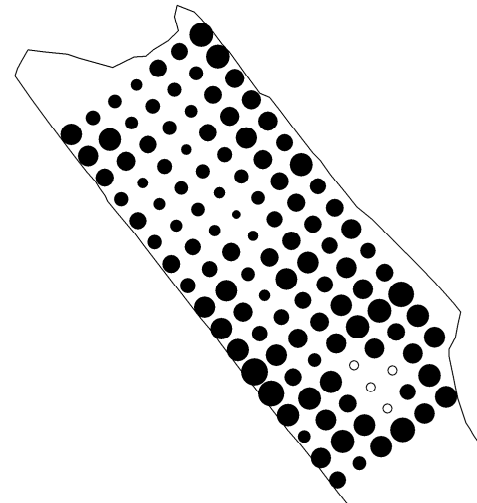

PROPGRASS

2009
PROPGRASS

2011

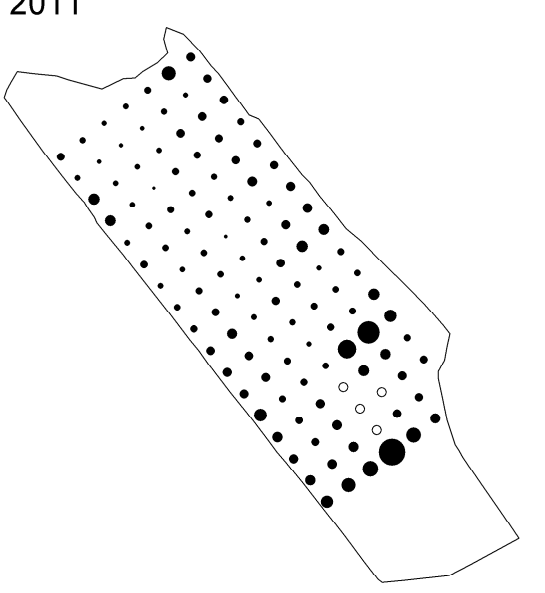

Figure S10 


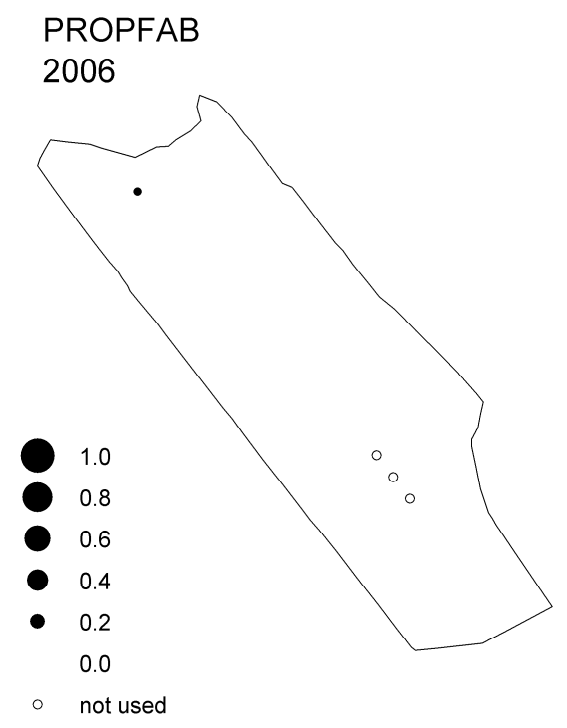

PROPFAB

2010

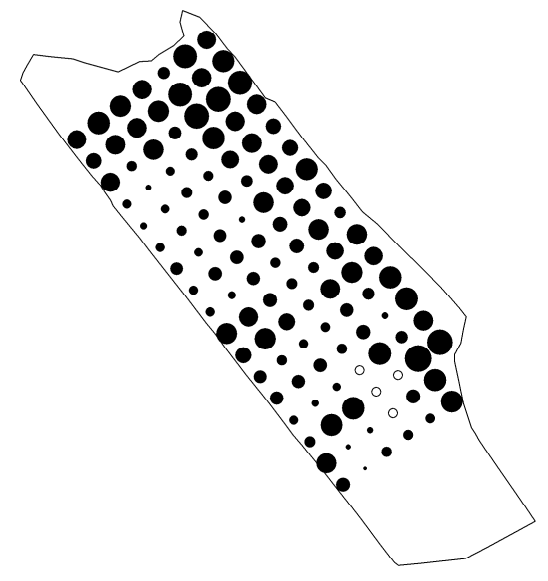

PROPFAB

2007

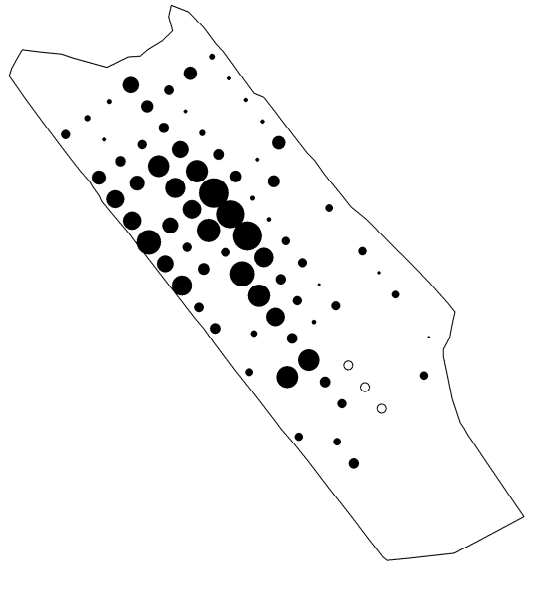

PROPFAB

2011

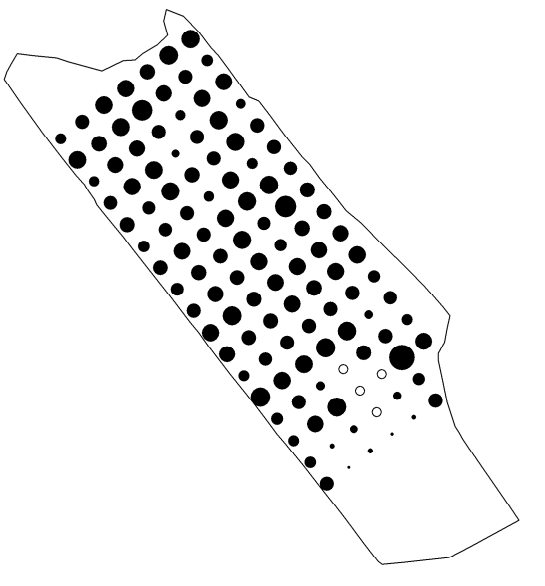

PROPFAB

2008

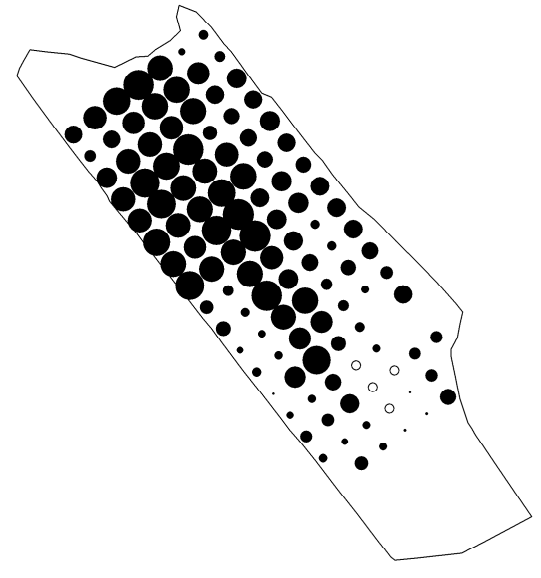

PROPFAB

2009

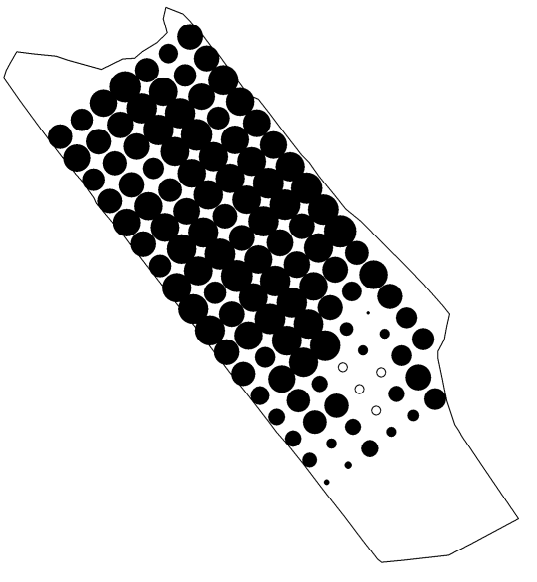

Figure S11 

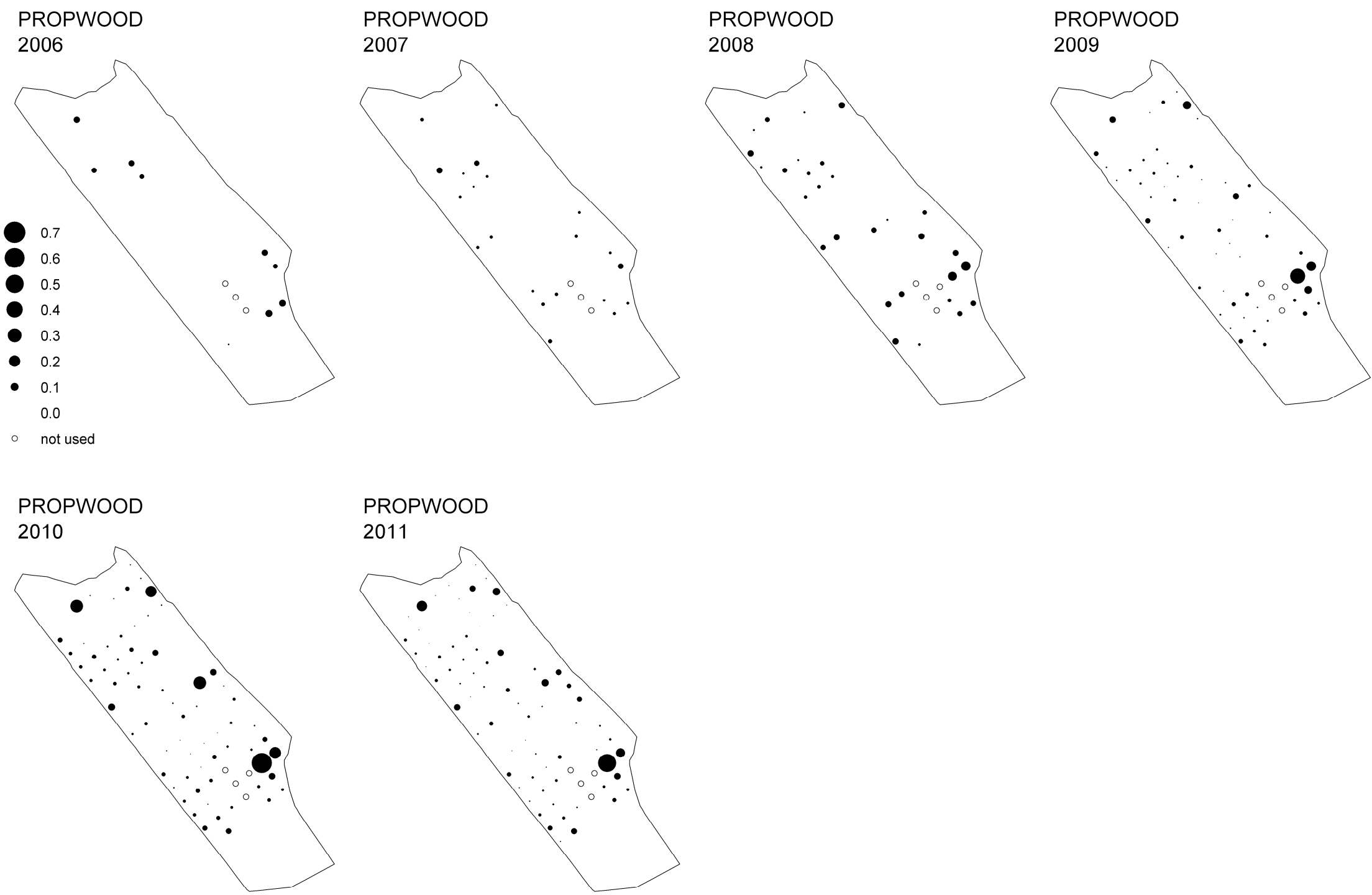

Figure S12

15 


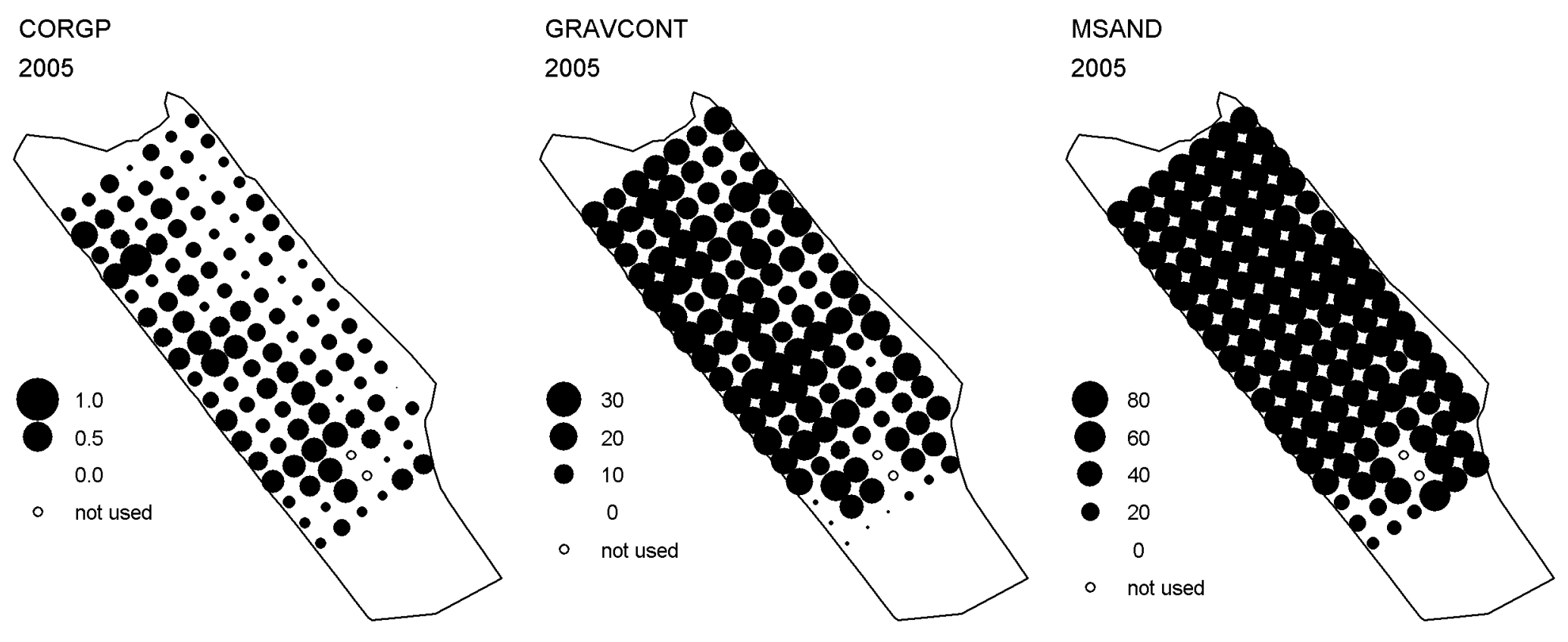

Figure S13 
2006

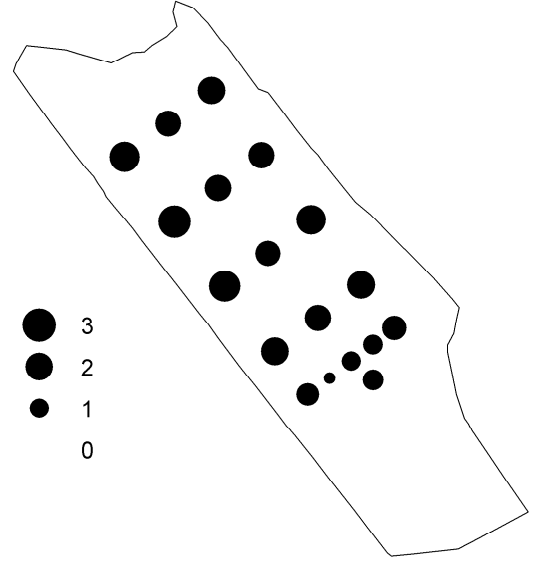

GAUGE

2010

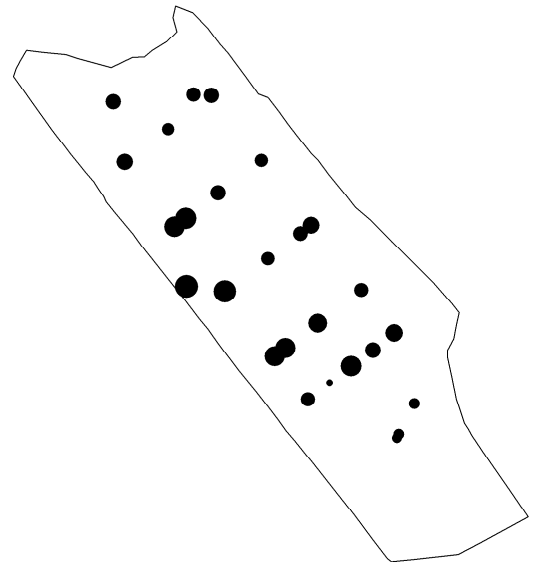

GAUGE

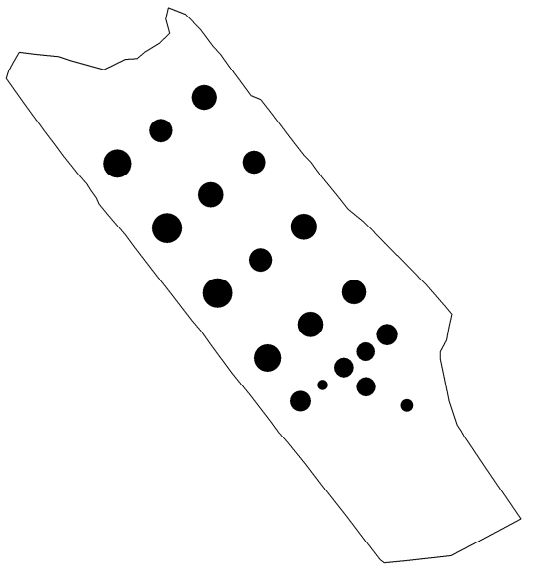

GAUGE

2008

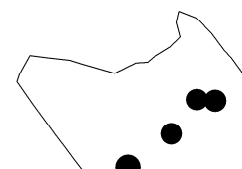

10

$0^{\circ}$

0
GAUGE

2009

GAUGE

2011

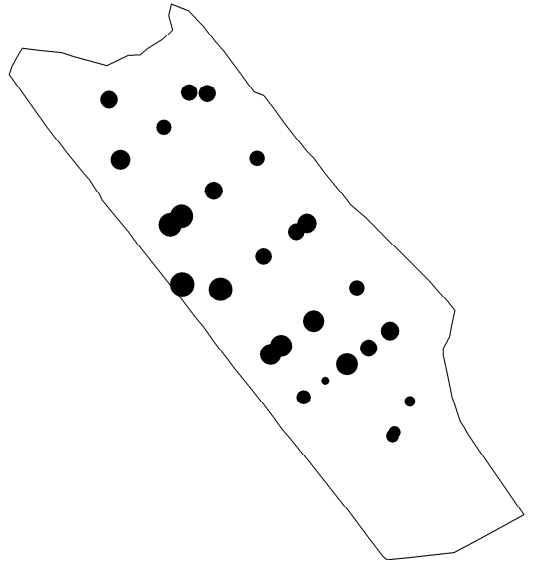

Figure S14 



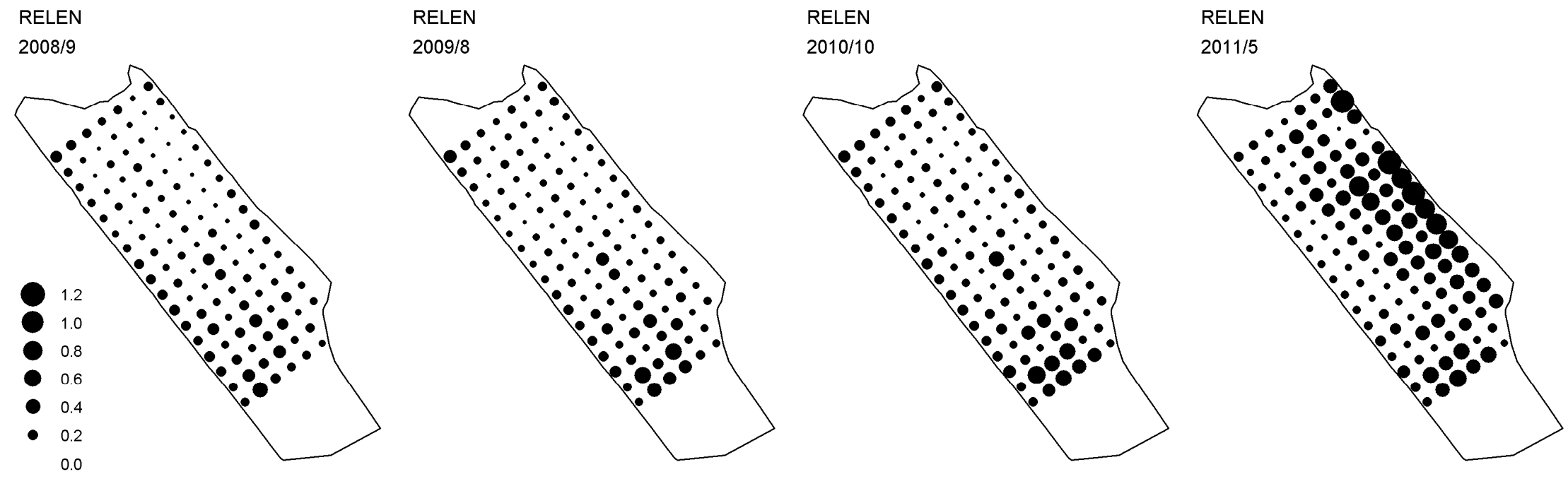

Figure S19

20 

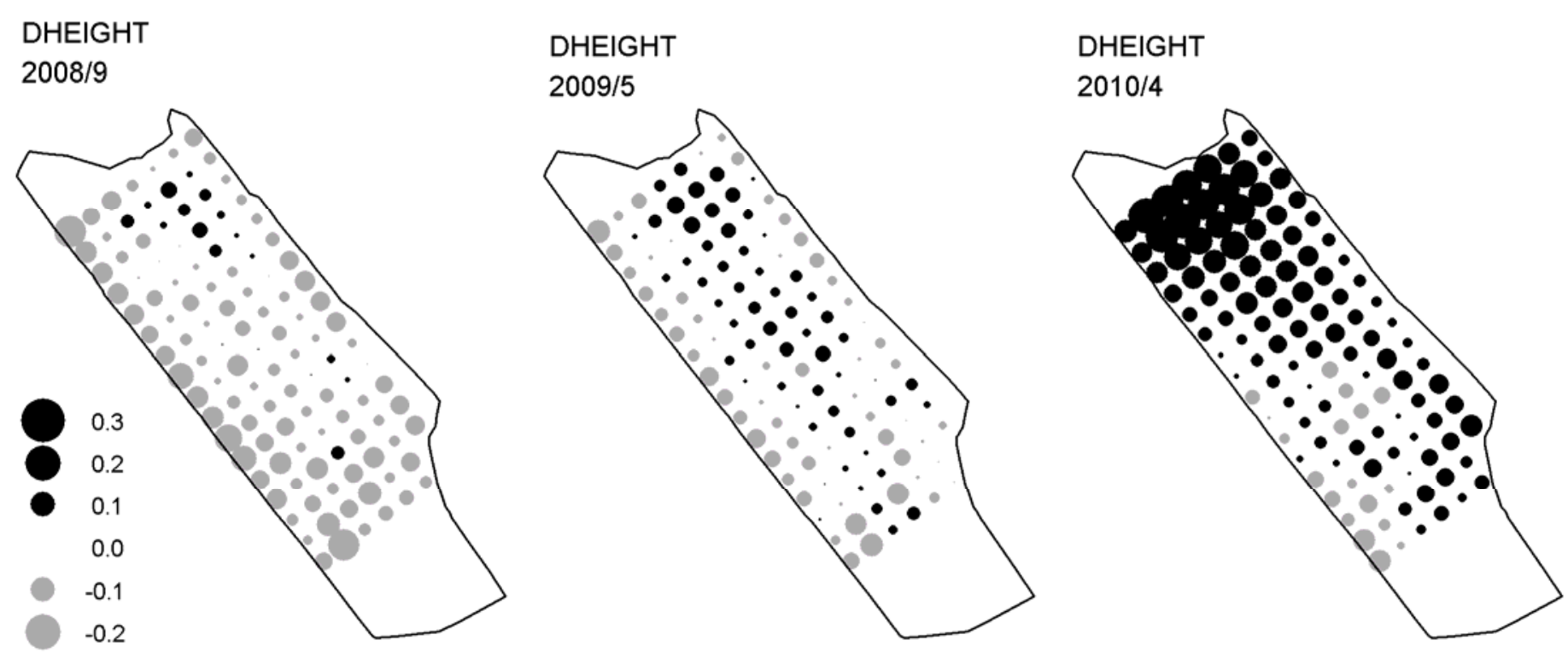

Figure S20 


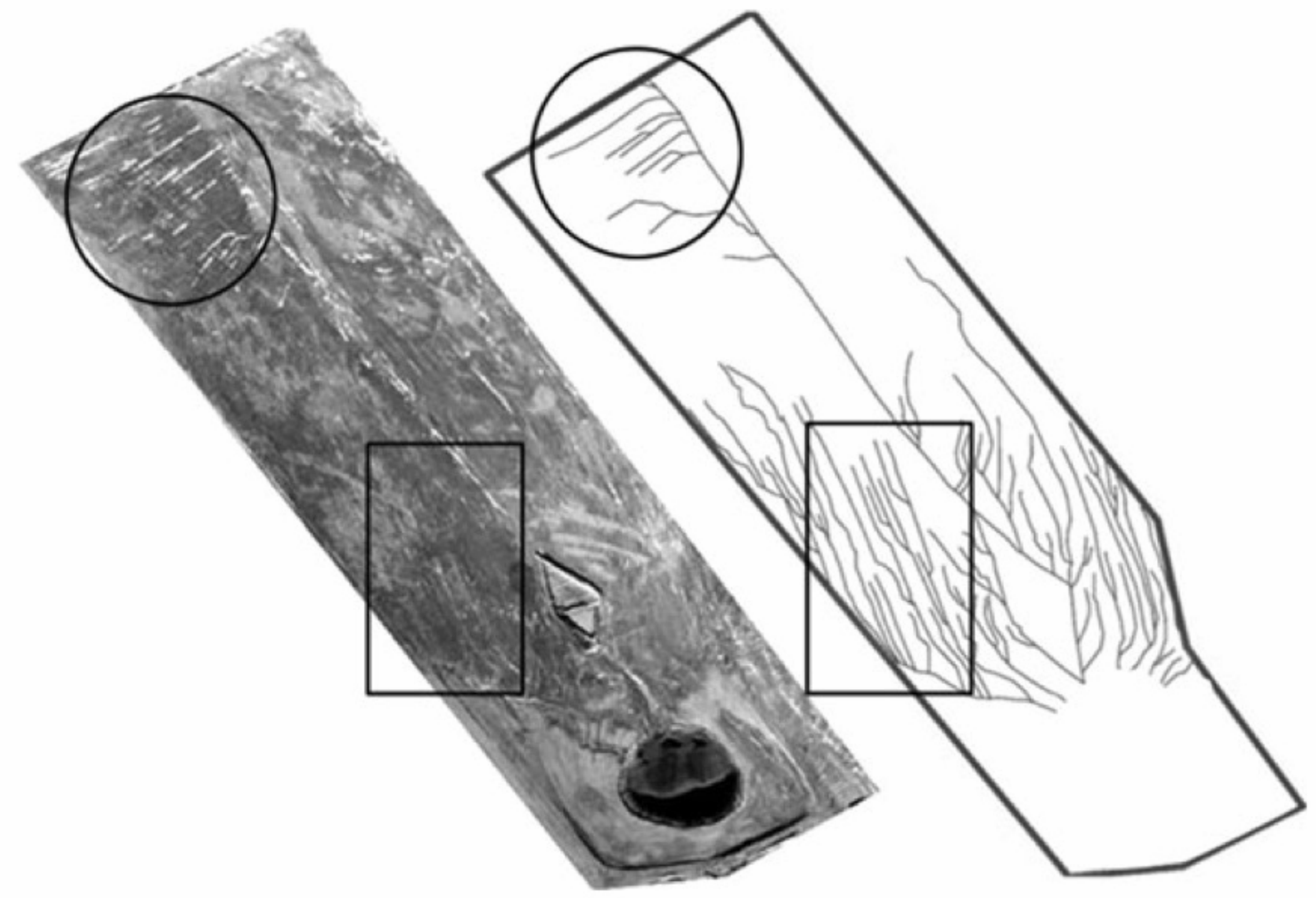

Figure S21 
$2008 / 9$

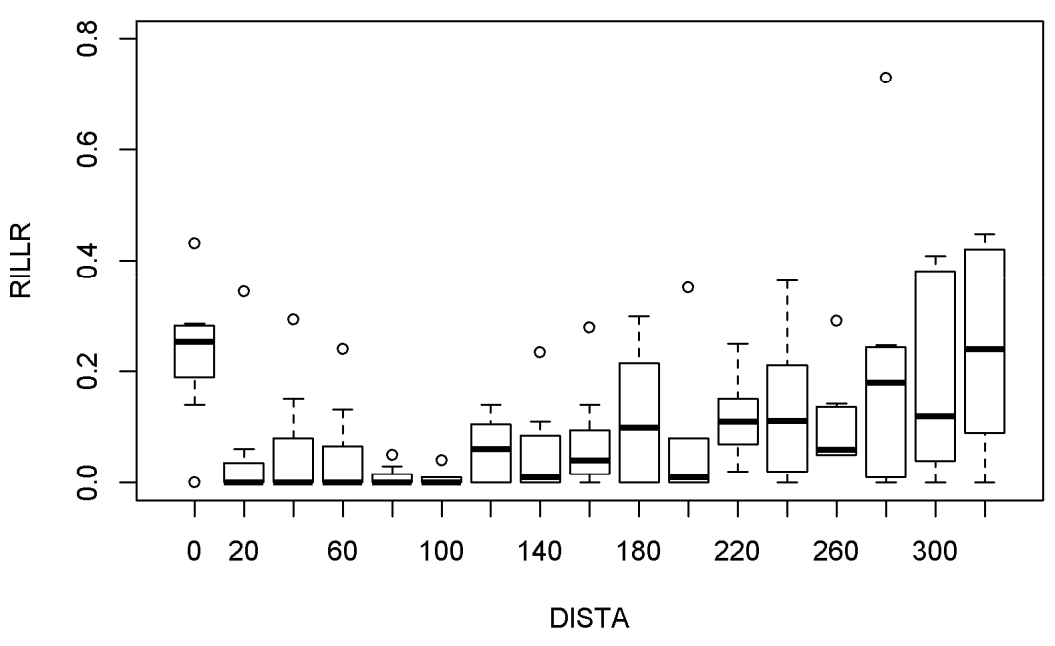

2010/10

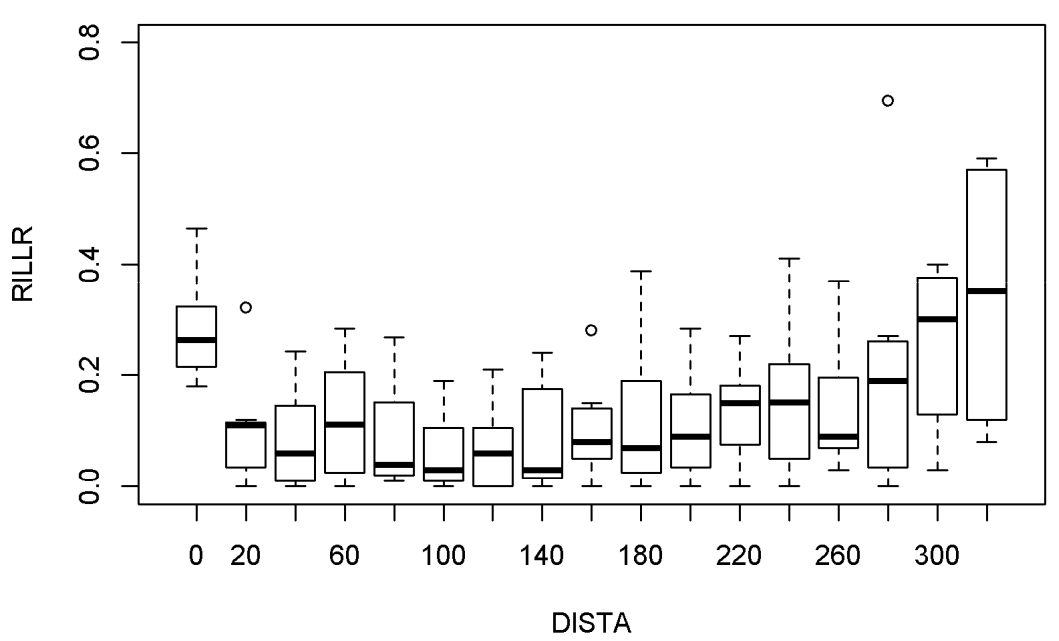

2009/8

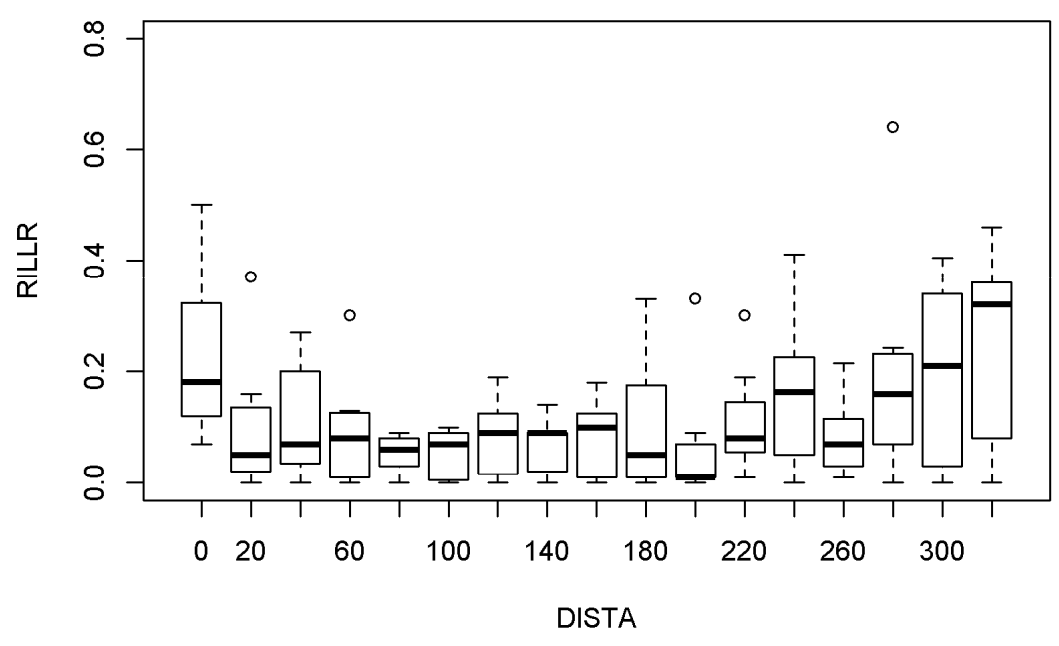

2011/5

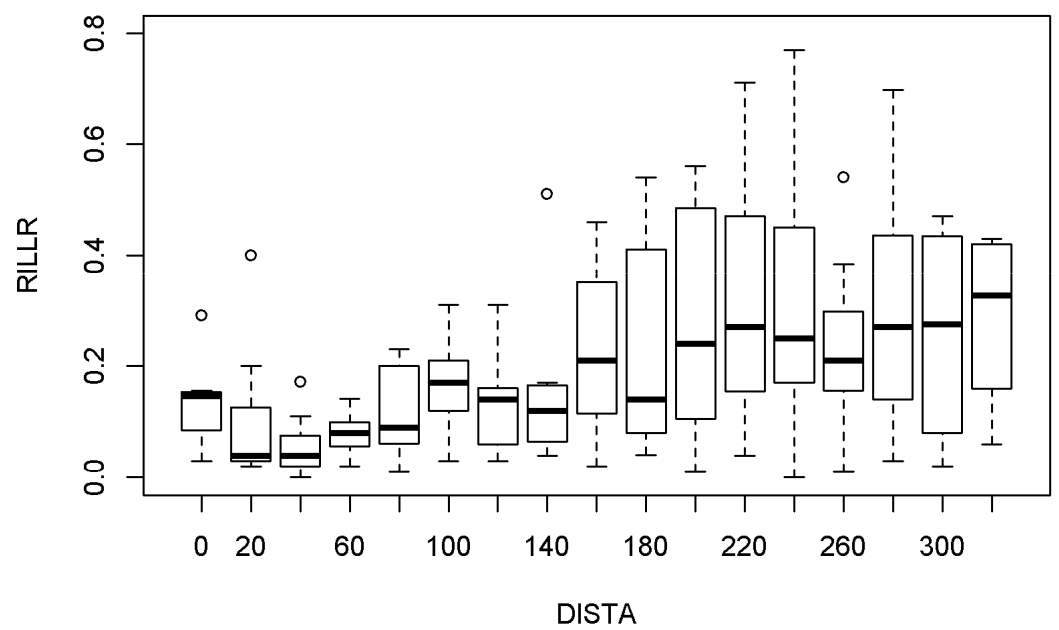

Figure S22 
$2008 / 9$

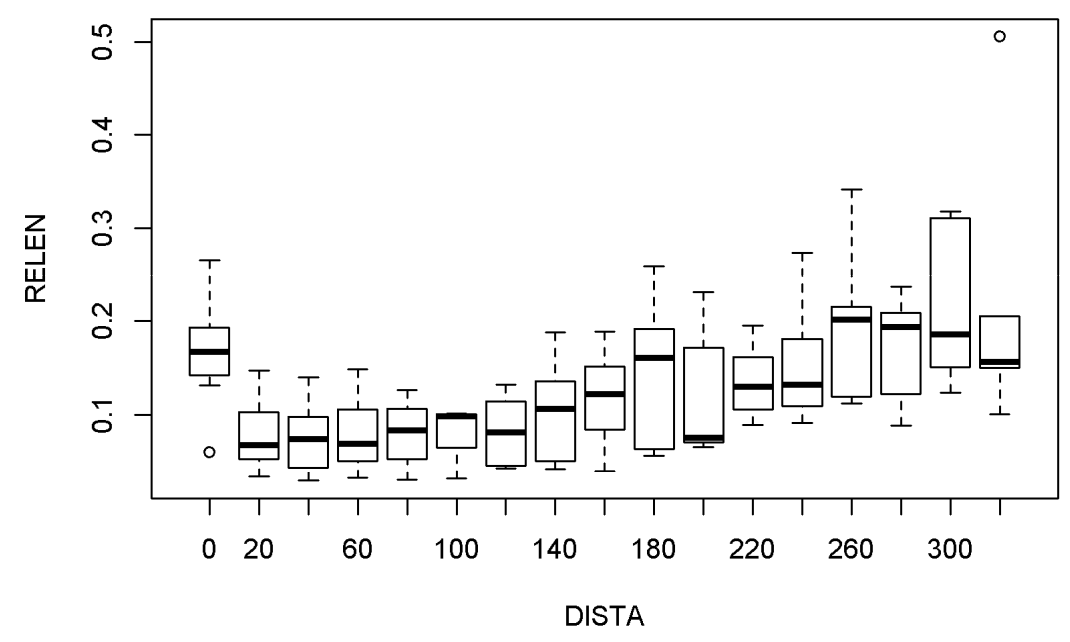

2010/10

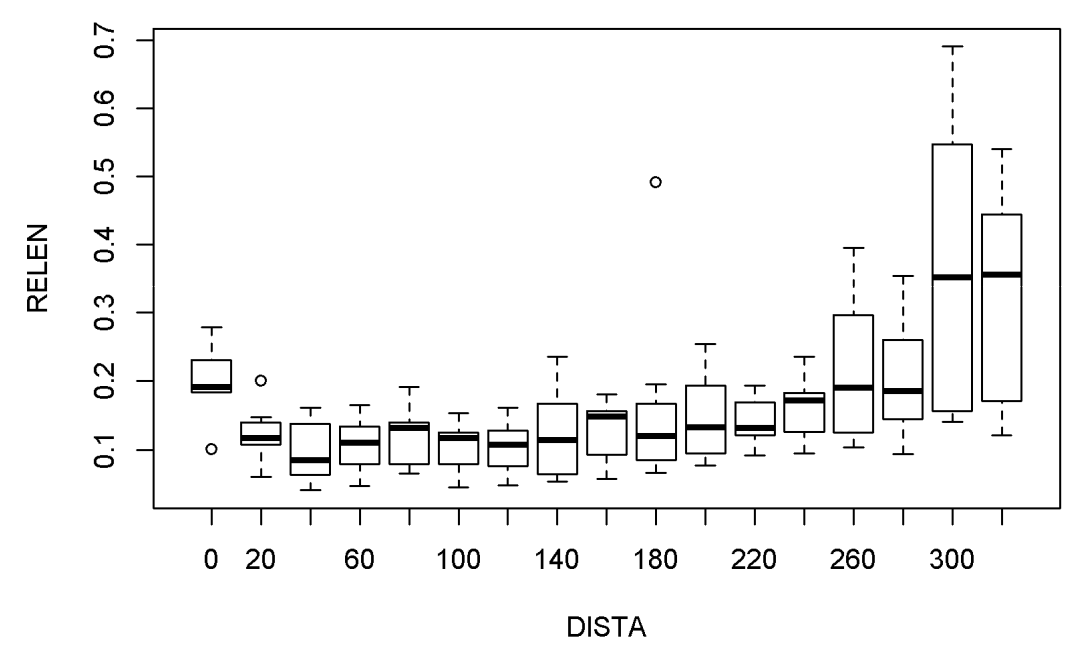

2009/8

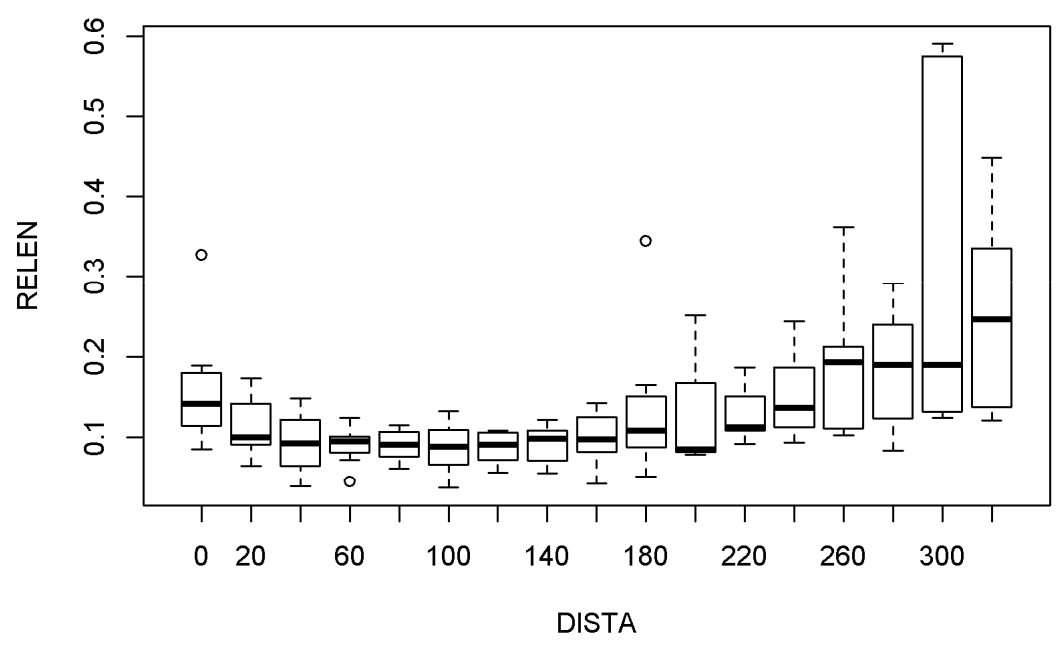

2011/5

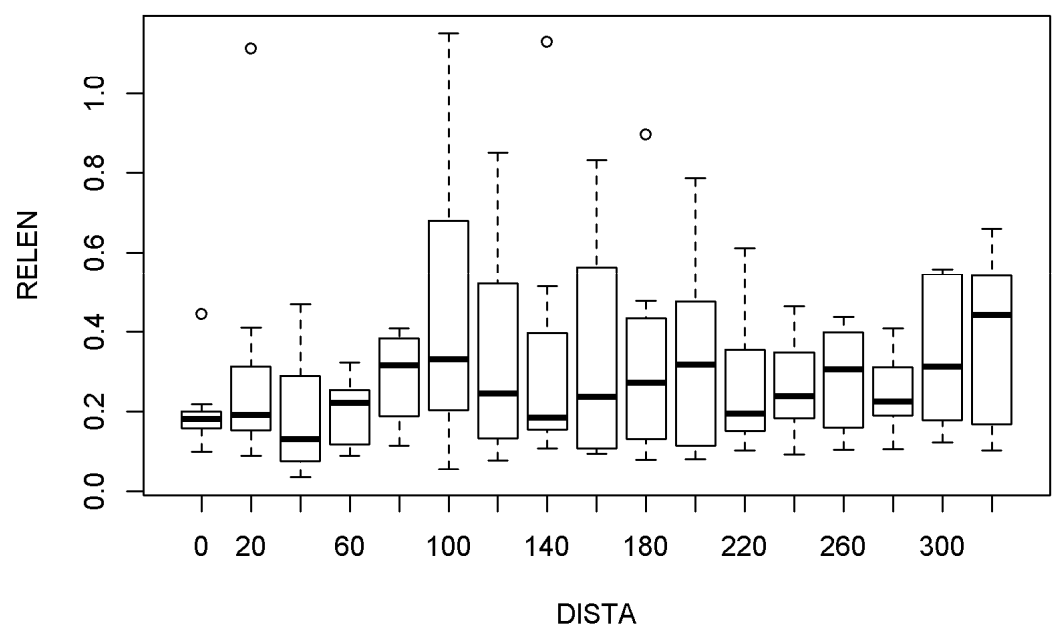

Figure S23 